\title{
Assessment of drug utilization among geriatric patients based on defined daily dose concept in a rural tertiary care teaching hospital
}

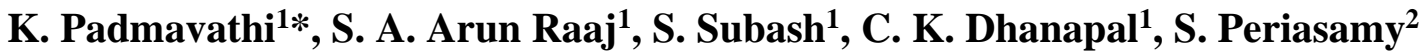

\author{
${ }^{1}$ Department of Pharmacy, Annamalai University, Annamalai Nagar, Tamil Nadu, India \\ ${ }^{2}$ Department of Medicine, Rajah Muthiah Medical College and Hospital, Annamalai University, Annamalai Nagar, \\ Tamil Nadu, India
}

Received: 20 July 2020

Accepted: 31 August 2020

\section{*Correspondence:}

Dr. K. Padmavathi,

Email: sumahari466@gmail.com

Copyright: (C) the author(s), publisher and licensee Medip Academy. This is an open-access article distributed under the terms of the Creative Commons Attribution Non-Commercial License, which permits unrestricted non-commercial use, distribution, and reproduction in any medium, provided the original work is properly cited.

\begin{abstract}
Background: The objectives of the study were to use the anatomical therapeutic chemical classification (ATC) /defined daily dose (DDD) concept to study the drug utilization pattern in geriatric patients in a rural tertiary care teaching hospital.

Methods: An observational study was conducted at Rajah Muthiah Medical College Hospital (OPD and IPD) over a period of six months from November 2018 to April 2019. The data was collected from 204 patients using specially designed data collection form. The patients were selected based on inclusion and exclusion criteria.

Results: A total of 204 patients were included in this study. The study population consisting of males $130(63.7 \%)$ and females $74(36.2 \%)$. Diseases related to the cardiovascular system 67 (32.84\%) were the most common cause for the geriatric patients to attend the hospital, followed by surgical diseases 47 (23.03\%), Oncological diseases 2 $(0.98 \%)$ were the least frequency encountered. The average number of drugs prescribed per prescription was 8.79 . Out of 1795 drugs prescribed, $60.86 \%$ of drugs were prescribed in generic form, and $39.14 \%$ were prescribed in brand name. The study analysed that $71.25 \%$ of drugs prescribed were from essential drug list (EDL) 2016-2018. Number of prescriptions with an injection was 74.04\%. Paracetamol (N02B01) was the most frequently prescribed drug, followed by Amlodipine (C08CA01), Dexamethasone (H02AB02), Clopidogrel (B01AC04), Ferrous sulfate (B03AA07), Acetylsalicylic acid (B01AC06), Hydrocortisone (H02AB09), Tamsulosin (G04CA02), Atorvastatin (C10AA05), Furosemide (C03CA01).

Conclusions: Drug utilization study can help in evaluating the quality of care given to the geriatric patients and promote rational use of medicines.
\end{abstract}

Keywords: ATC/DDD system, Drug utilization pattern, Geriatric patients

\section{INTRODUCTION}

Drug utilization research is invaluable tool for all involved in drug and health policies and related decisionmaking. Drug utilization is defined by World Health organization (WHO) as "marketing, distribution, prescription and use of drugs in a society, with special emphasis on the resulting medical, social and economic consequences". ${ }^{1}$ Research on drug utilization focus on factors related to prescribing, dispensing, administering and taking of medication and its associated events.

The ultimate purpose of drug utilization research is to contribute the optimal quality of drug therapy by Rational use of drug requires that patient receive medication appropriate to their clinical needs, in dose that meet their own individual requirements for the adequate period and 
the lowest cost to them and their community, identifying, documenting, analysing problems in drug utilization and monitoring the consequences. There are many factors underlying irrational use of drugs. The major factors can be patients, prescribers, work place and supply system. Therefore, it is important to recognize negative consequences of inappropriate drug use to promote rational use of drug. ${ }^{2}$

In 1981, the ATC/DDD system was recommended by WHO as the international standard for drug utilization studies. The ATC/DDD system is used to access the standardized and validated information on drug use and it is essential to allow audit of patterns of drug utilization, identification of problems, educational or other interventions and monitoring of the outcomes of the interventions. The purpose of the ATC/DD system is to serve as a tool for drug utilization monitoring and research in order to improve quality of drug use. An important aim of drug utilization is to monitor rational as well as irrational drug use as an important step in improving the quality of drug use. The DDD is the assumed average maintenance dose per day for a drug used for its main indication in adults". DDD is a unit of measurement and does not necessarily reflect the recommended or Prescribed Daily Dose. Therapeutic doses for individual patients and patient groups will often differ from the DDD as they will be based on individual characteristics (such as age, weight, ethnic differences, type and severity of disease) and pharmacokinetic considerations. ${ }^{3}$

Considering the physiological changes that occur with aging and its impact factor on the pharmacokinetics and Pharmacodynamic of drugs, it is essential to monitor drug effects, especially adverse drug reactions (ADR) and drug interactions, and clinical outcome in geriatric patients. ${ }^{4}$ To understand these processes better and in order to make the drug use rational and use safer, it is necessary to study the pattern of drug use in geriatric patients. ${ }^{5}$ As the number of medicines taken by geriatric patient is high, the incidence of ADR is more in this age-group, then it becomes increasingly more important to study drug use pattern.

For these reasons we undertook this study with the broad aim of understanding and analysing the Drug Utilization Pattern in geriatric patients in a rural tertiary care teaching hospital.

\section{METHODS}

A record based observational study was conducted at Rajah Muthiah Medical College and Hospital, rural 1400bed multispecialty, tertiary care teaching hospital, Annamalai University, Annamalai Nagar, Tamil Nadu, from the period of November 2018 to April 2019.

\section{Sample size}

A total 204 patients of geriatric age group of both genders who has crossed 60 years of age were included in the study. It is calculated as follows.

$$
\mathrm{N}=\frac{\mathrm{Z}^{2} \times \mathrm{P}(1-\mathrm{P})}{\mathrm{d}^{2}}
$$

\section{Inclusion criteria}

Patients of both gender who has crossed 60 years of age and who are admitted in the Department of Medicine, Surgery, Obstetrics and Gynaecology, DVL, ENT, Ophthalmology, Orthopaedics and Psychiatric.

\section{Exclusion criteria}

Patients unable to communicate i.e., Patients on ventilators or critically ill (Coma) patients requiring ICU admission and patients who are not willing to participate.

\section{Analysis of drugs}

Data were analysed for WHO prescribing indicators like Average number of drugs per prescription, Percentage of drug prescribed in Generic name, Number of drugs prescribed from NLEM (2015); Number of drugs prescribed from EDL (2016-2018) and Percentage of prescriptions with injection. The top ten most commonly prescribed drugs were identified and were given ATC codes. $^{6}$

The DDD of these drugs was calculated according to the WHO ATC/DDD system based on DDD's/1000 inhabitants per day. ${ }^{6}$

Utilization in DDD: (No. of packages used) $\times$ (No. of DDD in a package)

DDDs/1000 inhabitants/day:

$$
\begin{aligned}
& \frac{(\text { Utilization in DDDs })}{(\text { no. of inhabitants })} \times 1000 \\
& \times(\text { no. of days in the period of data collection })
\end{aligned}
$$

\section{Statistical analysis}

Data was entered and analysed with Microsoft excel 2007. Descriptive statistics were used to analyze the results. Percentage and averages of the variable were also calculated to compare the data with other findings.

\section{RESULTS}

Total of 204 patients were included in this study, consisting of male $130(63.7 \%)$ and females $74(36.2 \%)$ and majority of the patients were in the age group of 60 $65(60.2 \%), 66-70(18.1 \%), 71-75(11.7 \%), 76-80(7.8 \%)$ and $>80(1.9 \%)$ were given in Table 1 . 
A total of 352 disease conditions were prevalent in geriatric patients. Diseases related to cardiovascular system $(67 ; 32.84 \%)$ were the most common cause for attending the hospital followed surgical diseases $(47 ; 23.03 \%)$, Oncological diseases $(2 ; 0.98 \%)$ were the least most frequently encountered, and it is mentioned in Table 2.

Table 1: Age-wise distribution.

\begin{tabular}{|lll|}
\hline Age (years) & $\begin{array}{l}\text { No. of } \\
\text { patients }\end{array}$ & $\begin{array}{l}\text { Percentage } \\
(\%)\end{array}$ \\
\hline $\mathbf{6 0 - 6 5}$ & 123 & 60.2 \\
\hline $\mathbf{6 6 - 7 0}$ & 37 & 18.1 \\
\hline $\mathbf{7 1 - 7 5}$ & 24 & 11.7 \\
\hline $\mathbf{7 6 - 8 0}$ & 16 & 7.8 \\
\hline $\mathbf{> 8 0}$ & 4 & 1.9 \\
\hline
\end{tabular}

Table 2: Disease conditions prevalent in geriatric patients.

\begin{tabular}{|lll|}
\hline Disease conditions & $\begin{array}{l}\text { No. of } \\
\text { diseases }\end{array}$ & $\begin{array}{l}\text { Percentage } \\
(\%)\end{array}$ \\
\hline $\begin{array}{l}\text { Cardiovascular } \\
\text { diseases }\end{array}$ & 67 & 32.84 \\
\hline Surgical diseases & 47 & 23.03 \\
\hline Infectious diseases & 36 & 17.64 \\
\hline $\begin{array}{l}\text { Musculoskeletal } \\
\text { diseases }\end{array}$ & 35 & 17.15 \\
\hline Endocrinal disease & 34 & 16.66 \\
\hline Respiratory disease & 30 & 14.70 \\
\hline Ocular diseases & 24 & 11.76 \\
\hline $\begin{array}{l}\text { Dermatological } \\
\text { diseases }\end{array}$ & 19 & 9.31 \\
\hline ENT diseases & 19 & 9.31 \\
\hline Psychiatric diseases & 13 & 6.37 \\
\hline Others & 13 & 6.37 \\
\hline CNS diseases & 8 & 3.92 \\
\hline $\begin{array}{l}\text { Gynaecological } \\
\text { diseases }\end{array}$ & 5 & 2.45 \\
\hline Oncological diseases & 2 & 0.98 \\
\hline Total & 352 & \\
\hline
\end{tabular}

Department-wise distribution of patients and drug use among them. Average number of drugs per prescription was 8.77. The highest average number of drugs per prescription was seen in dermatology and venereology department (14.72) and lowest average number of drugs per prescription was in the ophthalmology department (2.95) were shown in Table 3.

Table 3: Department-wise distribution of patients and drug use among them.

\begin{tabular}{|llll|}
\hline Department & $\begin{array}{l}\text { No. of } \\
\text { patients }\end{array}$ & $\begin{array}{l}\text { Total no. } \\
\text { of drug } \\
\text { prescribed }\end{array}$ & $\begin{array}{l}\text { Avg no. of } \\
\text { drugs per } \\
\text { prescription }\end{array}$ \\
\hline Medicine & 58 & 530 & 9.13 \\
\hline Surgery & 46 & 398 & 8.65 \\
\hline Orthopaedics & 24 & 214 & 8.91 \\
\hline Ophthalmology & 22 & 65 & 2.95 \\
\hline ENT & 19 & 176 & 9.26 \\
\hline $\begin{array}{l}\text { Dermatology } \\
\text { and } \\
\text { venereology }\end{array}$ & 18 & 265 & 14.72 \\
\hline Psychiatrics & 10 & 91 & 9.1 \\
\hline $\begin{array}{l}\text { Urology } \\
\text { Obstetrics and } \\
\text { gynaecology }\end{array}$ & 4 & 29 & 7.25 \\
\hline Total & 3 & 27 & 9 \\
\hline
\end{tabular}

WHO prescribing indicators like average number of drugs per prescription (8.79), percentage of drug prescribed in Generic name $(60.86 \%)$ and number of drugs prescribed from NLEM-2015 (71.25\%), no. of drugs prescribed from EDL-2016 to 2018 were $(69.47 \%)$ and percentage of prescriptions with injection $(74.01 \%)$ were shown in Table $4 .^{7-9}$

Table 4: WHO prescribing indicators.

\begin{tabular}{|lll|}
\hline Prescribing indicator & $\begin{array}{l}\text { Values } \\
\text { obtained } \\
(\%)\end{array}$ & $\begin{array}{l}\text { WHO } \\
\text { standards } \\
(\%)\end{array}$ \\
\hline $\begin{array}{l}\text { Average number of drugs } \\
\text { per prescription }\end{array}$ & 8.799 & 1.6 to 4.8 \\
\hline $\begin{array}{l}\text { Percentage of drug } \\
\text { prescribed in generic }\end{array}$ & 60.86 & 100 \\
\hline $\begin{array}{l}\text { Number of drugs } \\
\text { prescribed from National } \\
\text { List of Essential Medicines } \\
\text { (NLEM)-2015 }\end{array}$ & 71.25 & 100 \\
\hline $\begin{array}{l}\text { Number of drugs } \\
\text { prescribed from Essential } \\
\text { Drug List (EDL) 2016- } \\
\text { 2018 }\end{array}$ & 69.47 & 100 \\
\hline $\begin{array}{l}\text { Percentage of prescriptions } \\
\text { with injection }\end{array}$ & 74.01 & $13.4-24.1$ \\
\hline
\end{tabular}

Table 5: Ten most frequently prescribed drugs and ATC/DDD codes.

\begin{tabular}{|lllll|}
\hline ATC code & Drug & WHO DDD $(\mathbf{m g})$ & DDD & DDDs/1000 inhabitants/day \\
\hline N02BE01 & Paracetamol & $3 \mathrm{~g}$ & 139.83 & 3.808 \\
\hline C08CA01 & Amlodipine & 5 & 135 & 3.6765 \\
\hline H02AB02 & Dexamethasone & 1.5 & 125.33 & 3.4131 \\
\hline B01AC04 & Clopidogrel & 75 & 123 & 3.3497 \\
\hline
\end{tabular}




\begin{tabular}{|lllll|}
\hline ATC code & Drug & WHO DDD $(\mathbf{m g})$ & DDD & DDDs/1000 inhabitants/day \\
\hline B03AA07 & Ferrous sulfate & $0.2 \mathrm{~g}$ & 121 & 3.2952 \\
\hline B01AC06 & Acetylsalicylic acid & 1 tab $(=1$ unit dose $)$ & 98 & 2.6688 \\
\hline H02AB09 & Hydrocortisone & 30 & 86.66 & 2.36 \\
\hline G04CA02 & Tamsulosin & 0.4 & 82 & 2.2331 \\
\hline C10AA05 & Atorvastatin & 20 & 74.5 & 2.0289 \\
\hline C03CA01 & Furosemide & 40 & 73 & 1.988 \\
\hline
\end{tabular}

The most frequently prescribed drugs were Paracetamol, Amlodipine, Dexamethasone followed by Clopidogrel, Ferrous sulphate, Acetylsalicylic acid, Hydrocortisone, Tamsulosin, Atorvastatin and Furosemide and these drugs were given ATC code were shown in Table 5.

\section{DISCUSSION}

The geriatric population is on the rise worldwide. This population is vulnerable to many diseases and drugrelated problems. Limited data are available in general, particular in India, on drug utilization in this population. ${ }^{5}$ We undertook this study in order to understand the pattern of drug use and drug related issues in geriatric patients.

\section{Disease condition}

A total of 352 disease conditions were prevalent among these patients. Diseases related to the cardiovascular system 67 (32.84\%) were the most common cause for the geriatric patients to attend the hospital, followed by surgical diseases $47(23.03 \%)$. Oncological diseases 2 $(0.98 \%)$ were the least frequency encountered. This is supported by the fact that the prevalence of hypertension in the last six decades has increased from $2 \%$ to $25 \%$ among urban residents and from $2 \%$ to $15 \%$ among the rural residents in India. ${ }^{10}$

\section{Analysis WHO-prescribing indicators}

\section{Average number of drugs per prescription}

A number of drugs prescribed per prescription was 8.79 is slightly higher than that observed by Anitha et al (7.02) This deviates from the WHO standards of 1.6 to $4.8^{11}$ The minimum number of drugs per prescription was three and the maximum number of drugs per prescription was 31. The number of drugs was increasing with the increasing in number of hospital stay days. The highest number of drugs per prescription was seen in the DVL department (14.72) and the lowest number of drugs per prescription was in the ophthalmology department (2.95).

Of these 204 patients, $41(20.09 \%)$ were taking less than five medicines per day and $163(79 \%)$ patients were prescribed more than five medicines per day. This indicates that majority of patients in our study were having Polypharmacy.
In this study, 1795 drugs were prescribed to a total of 204 patients for different diseases which consist of $17.93 \%$ of Fixed dose combinations (FDCs) that is more or less coincide with study reported by Kolhe et al $(18.35 \%) .{ }^{12}$ FDCs increase the risk of drug interactions and ADRs. However, the use of FDCs can improve compliance with therapy by decreasing the number of formulations to be taken. The risk/benefit ratio should be assessed before prescribing FDCs. ${ }^{13}$

\section{Number of drugs prescribed with generic name}

Out of 1795 drugs prescribed, $60.86 \%$ of drugs were prescribed in generic form, $39.14 \%$ were prescribed in brand name, this is much more as compared to the findings of Kolhe et al (22.64\%). ${ }^{12}$ But still falls short of the WHO recommendation of $100 \%$. This shows the free medicines offered in the government hospital located in rural areas are generic drugs, which is highly appreciable. However, still there is a need to encourage prescribing by generic names. Prescribing by generic name allows flexibility of stocking and dispensing various brands of a particular drug that are cheaper than and as effective as proprietary brands.

\section{Number of drugs prescribed from EDL and NLEM}

$71.25 \%$ of drugs prescribed were from Essential Drug list (EDL-2016-2018). 69.47\% of drugs prescribed were from National List of Essential Medicines (NLEM-2015), which is the reason why there was a very good positive outcome in patients during the treatment period.

\section{Number of prescriptions with an injection}

Number of prescriptions with an injection was $74.04 \%$ which is in conformity with study conducted by and much higher than the study by Shantadurga S Kerkar et al. ${ }^{14}$ Advantage of parenteral drugs is their ability to enhance drug adherence.

\section{$D D D$}

DDD is the criteria used to compare utilization of drug at international level. We used this parameter to study drug use based on dose. We calculated DDD for the drugs that were prescribed to study participants. Importance given was according to the disease condition prevalence in our study, mainly cardiovascular diseases and surgical diseases. 
Based on ATC, DDD is calculated is for blood and blood forming organs (B), cardiovascular system (C), Genito urinary system and sex hormones (G), Systemic hormonal preparations (excluding sex hormones and insulin) $(\mathrm{H})$ and nervous system $(\mathrm{N})$, and the most commonly utilized ten drugs were Paracetamol (N02B01), Amlodipine (C08CA01), Dexamethasone (H02AB02), Clopidogrel (B01AC04), Ferrous sulfate (B03AA07), Acetylsalicylic acid (B01AC06), Hydrocortisone (H02AB09), Tamsulosin (G04CA02), Atorvastatin (C10AA05), Furosemide (C03CA01).

Based on ATC, Paracetamol (N02B01) comes under analgesics and anti-pyretic, is being prescribed for fever and it is a NSAID's. Amlodipine (C08CA01) comes under blood and blood forming agents, as selective calcium channel blocker with mainly vascular effects and also Atorvastatin (C10AA05) and Furosemide (C03CA01). Calcium channel blocker drugs were the most frequently prescribed drug group for hypertension in our study as also in a similar study done by Patel VJ, though recent guidelines suggest that thiazide diuretics should be the drugs of first choice for treatment of hypertension in elderly (with calcium channel blockers being the drugs of second choice). ${ }^{15,16}$

Dexamethasone (H02AB02) and Hydrocortisone (H02AB09) comes under systemic hormonal preparations (excluding sex hormones and insulin) and particularly corticosteroids for systemic use. This is prescribed as glucocorticoids. Clopidogrel (B01AC04), Ferrous sulfate (B03AA07), acetylsalicylic acid (B01AC06), belongs to blood and blood forming agents. Tamsulosin (G04CA02), Genito-urinary system and sex hormones-Urological (Drugs used in benign prostatic hypertrophy).

We calculated DDD for geriatric patients and more importance were given to cardiovascular diseases because in our study prevalence of cardiovascular diseases is more. Sample size of the study is small and study period is six months. These can be considered as limitations of our study but nevertheless, the study findings cannot be considered any less important.

\section{CONCLUSION}

In conclusion, this study has shown the patterns of diseases prevalent in geriatric patients and drug use among them. Drug utilization studies of this type may ultimately help in improving the quality of healthcare given to the geriatric patients and help in improving rational use of medicines.

\section{ACKNOWLEDGEMENTS}

Author would like to thank to Rajah Muthiah Medical College and Hospital for allowing to conduct the study. Also thank beloved parents S. Karunakaran and K. Sumathi and lovely brother K. Harikaran and encouraging friends for successfully completing this study.

Funding: No funding sources

Conflict of interest: None declared

Ethical approval: The study was approved by the Institutional Ethics Committee

\section{REFERENCES}

1. World health organization. Introduction to drug utilization. Available at https://apps.who.int/ medicinedocs/en/d/Js4876e/2.html. Accessed on 17 July 2020.

2. Dinesh Kumar Meena, M. Jayanthi-Drug utilization research: a review Int $\mathbf{J}$ of Basic Clinical Pharmacol. 2019;8(2):354-61.

3. WHO International Working Group for Drug Statistics Methodology, WHO Collaborating Centre for Drug Statistics Methodology and amp; WHO Collaborating Centre for Drug Utilization Research and Clinical Pharmacological Services. (2003). Introduction to drug utilization Research. WHO. https://apps.who.int/iris/handle/10 665/42627. Accessed on 17 July 2020.

4. Starner CI, Gray Sl, Guay DR, Hajjar ER, Handla SM Geriatrics. In: Dipiro ST, Talbert RL, Yee GC, Matzke GR, Wells BG, Posey LM, editors. Pharmacotherapy A pathophysiologic approach $7^{\text {th }}$ edition Newyork: Mc Graw Hill; 2008:57-66.

5. Shah RB, Gajjar BM, Desai SV. Drug utilization pattern among geriatric patients assessed with the anatomical therapeutic chemical classification/defined daily dose system in a rural tertiary care teaching hospital. Int J Nutr Pharmacol Neurol Dis. 2012;2(3):258-65.

6. World health organization. DDD indicators. Available at https://www.who.int/medicines/regulation/medicine s-safety/toolkit_indicators/en/index1.html.

Accessed on 17 July 2020.

7. World health organization. Prescribing indicators. Available https://apps.who.int/medicinedocs/en/d/Js2289e/3.1. html. Accessed on 17/8/2020.

8. National List of Essential Medicines-2015 Central Drugs Standard. Available at: http://www.cdsco.nic.in/National $\% 20$ List $\% 20$ of $\% 20$ Essential\%20Medicine-\%20final $\% 20$ copy. pdf. Accessed on 17 July 2020.

9. WHO Model Lists of Essential Medicines 20162018. Available at: http://www.who.int/medicines/ publications/ essential medicines. Accessed on 17 July 2020.

10. Association of Physicians of India. Indian guidelines on hypertension (I.G.H.)-III. 2013. J Assoc Physicians India. 2013;61(2):6-36. Available at: https://pubmed.ncbi.nlm.nih.gov/24475694/. Accessed on 17 July 2020. 
11. Nandagopal A, Koneru A, Rahman A, Pasha MD, Ali MKY. Assessment of Rational Drug Prescribing pattern in Geriatric Patients in Hyderabad Metropolitan. Ind J Pharm Pract. 2017;10(3):174-8.

12. Kolhe A, Kale AS, Padwal SL. Drug utilization study in geriatric patients at rural tertiary care hospital. Asian J Pharm Clin Res. 2015;8(4):90-92.

13. Nishandar TB, kale AS, Pise HN. Drug utilization pattern in geriatric patients attending outpatient department at rural tertiary care hospital in Maharashtra. Asian J Pharm Clin Res. 2017;10(2):314-6.

14. Patanaik SK, Pattanayak C, Prasad A, Chauhan AS. Drug utilization pattern in an intensive care unit setting in Eastern India. Int J Basic Clin Pharmacol. 2015;4(6):1136-41.
15. Patel VJ, Malhotra S, Gautam C. Drug use pattern of antihypertensive drugs in outdoor patients of a teaching hospital. Guj Med J. 2002;59:41-3.

16. Satoshkar RS, Bhandarkar SD, Rege NN. Pharmacology and Pharmacotherpaeutics. 20th ed. Mumbai: Popular Prakashan Private Limited; 2007:429.

Cite this article as: Padmavathi $\mathrm{K}$, Raaj SAA, Subash S, Dhanapal CK, Periasamy S. Assessment of drug utilization among geriatric patients based on defined daily dose concept in a rural tertiary care teaching hospital. Int J Basic Clin Pharmacol 2020;9:1538-43. 